\title{
Innovation Analysis of Huian Women's Dress under Modern Aesthetic Horizon
}

\author{
Shu-Yu Lin \\ Fujian Normal University Minnan Science and Technologygy Institute \\ Quanzhou City, Fujian Province, China
}

Keywords: Modern aesthetics; Huian women's dress; innovation

\begin{abstract}
Huian women's dress is the condensation of Huian women to the natural environment and the unique aesthetic, which is an unique mode of production, social customs and habits, culture and art formed in the process of continuous development and also a manifestation of regional culture in China. However, with the continuous progress and development of our society, the traditional Huian women's dress is changing with the aesthetic consciousness of modern people, which makes it unable to meet the daily needs of modernization of Huian women in the process of development. If the women's dress in Huian is not protected and inherited, it will gradually be flooded by the historical tide in the process of its development. Therefore, in order to further protect and inherit Huian women's dress culture, it is necessary to investigate and understand the aesthetic characteristics of the Huian women's dress and extract the design elements suitable for the modern design from it so that they can be adapted to the modern people's production and life style to achieve the effect of innovation. So, in order to do the related research work well, this article mainly analyzes the language and historical and cultural connotations of the Huian women's dress, the aesthetic commonness between Huian women's dress and modern dress and the innovative way of structure of Huian women's dress under the modern aesthetic horizon. In this way, the development of women's dress in Huian is further promoted.
\end{abstract}

\section{Introduction}

Because of the influence of the unique mode of production, customs, social customs and habits, arts and other regional culture in Huian in the long historical development process, unique Huian women's dress has formed in its process of continuous development. And with the development of the times, the Huian women's dress has gradually become a part of the Chinese traditional national dress culture. The Chinese traditional national dress culture is not only the inheritance of traditional folk culture, but also the witness of the mutual influence of multiracial dress culture in the process of the development of the times of Huian women's dress, having deep culture accumulation of dress, if it is inherited and developed, it will help to promote the further development of Chinese modern dress culture and promote the improvement of our people's aesthetic concept.

\section{The language and historical and cultural connotations of the Huian women's dress}

\subsection{The concept of Huian women's dress}

Huian women's dress refers to the folk costumes worn by the vast rural women in the eastern coastal areas of Huian, Fujian. Before the late Qing Dynasty, the Huian women's dress lacked sufficient text information in written records, and after the late Qing Dynasty, it had more specific records with the progress of the times. According to historical records, the original style of Huian women's dress mainly developed on the basis of sleeve shirt, but with the progress and development of the times, Huian women's dress gradually evolved towards the direction of sweatshirts and blouses and gradually formed the typical form of " Yellow bamboo hat, bright-colored headcloth, blouses, affixed to the back, silver waist chain, wide-leg trouser, embroidered slipper" of Huian women's dress, which fully reflected the folklore culture contained in it. 


\subsection{The cultural language of the Huian women's dress}

In the process of continuous development of Huian women's dress, it will be integrated with Huian women on the basis of the figure characteristics of Huian women, thus forming the dress features of beautiful proportions, peculiar shapes and colourful colors with unique folk dress culture[1]. Due to the influence of natural environment and social environment, land transportation in most areas of Fujian was blocked and they had extremely convenient water transportation as close to the offshore area. Therefore, in the process of development, the people in Huian all developed based on traditional fishery production. At the same time, with a certain amount of land, they will concurrently operate agriculture in order to maintain their daily life. In fishery production, Huian men are mainly responsible for fishing in the sea and Huian women are responsible for collecting, catching, farming and other daily works in fishery production, which makes their dress fully present the characteristics of the marine culture. Therefore, because of the influence of natural environment and cultural environment, Huian women show the typical Huian female image of "feudal head, democratic belly, saving clothes and long trousers in the process of development, the Huian women have became the best spokeswoman for the Huian women's dress, and have a certain cultural characteristics[2].

\section{The common manifestation of Huian women's dress and modern dress in aesthetic}

With the progress and development of the times, the traditional Huian women's dress cannot meet the daily needs of modernization of Huian women in its developmental process with the change of modern people's aesthetic consciousness, this demand is not only reflected in the daily wear, but also in the modern people's need for fashion and popularity of clothing. Therefore, at present, in order to further meet their own aesthetic needs and further inherit their own folklore personality, the young generation of Huian women find out the common manifestation of Huian women's dress and modern dress in aesthetic, so as to achieve the effect of innovation.

\subsection{Reflected in costume design}

As a visual art, in the process of designing, external styling design has been done for modern dress to make people have a profound visual impression in the process of appreciation of modern dress. With the development of the times, this way has gradually become the primary consideration in the overall design of dress. And in the aesthetic of modern clothing, as one of the basic forms of the outer contour of the dress, the A-profile is the mainstream aesthetic in the people's clothing aesthetics at present. And in this, simple and dignified design, the outline of smooth womanliness, starting from the narrow shoulders and gradually widening to hem, skirt reflect the popular elements of modern fashion. Huian women's dress are always with short upper outer garment and wide trousers, the upper outer garment tightening up the body and trousers loosing in design, which have a certain importance to the proportional aesthetic principle, so it has a very similar commonness of modern clothing in aesthetic with the popular elements and modern fashion.

\subsection{Reflected in the dressing way}

In modern dress designing, in order to ensure that the overall style of modern dress tends to be complete and unified in the process of design, clothing accessories are designed. The clothing accessories not only have a certain decoration function, but also can further increase the visual highlights, which is also of great help for the enhancement of the clothing style [3]. In the use of clothing accessories, Huian women's dress also has certain commonness with modern dress in clothing accessories. These practical clothing accessories such as small basket, golden hats and bright-colored headscarf long to the chest in Huian women's dress in the small basket, golden hats and long to chest headscarves not only have a certain exaggeration effect on the dimension, but also have a certain beauty. And in the daily wearing and matching, balance the volume of clothing and strengthen the appearance of clothing features. In this way, the Huian women's dress can produce combination of dynamic and static, comparison between big and small, which brings strong visual 
effect to people and has some similarities with modern aesthetics in this respect.

At the same time, this commonness is also reflected in the way of wearing. Huian women's dress has a certain layering in the design process, which is designed through the design method of superimposed dressing. The design of clothing in this way is mainly because of the small size of the Huian women, this way helps to avoid the plump and round visual effects of Huian women and conforms to the aesthetic tandard of the present young people, fully reflects the commonness of Huian women's dress and modern dress in aesthetic.

\section{The innovative way of the structure of Huian women's dress under the modern aesthetic horizon}

With the progress and development of the times, China has also joined the process of globalization. The stereoscopic design concept, scientific attitude and research on the relationship between clothing and human body of western costumes are also integrated into the dress designing in the production process of modern fashion clothing because of exchange and collision of eastern and Western culture [4]. Therefore, under the modern aesthetic horizon, in order to do well in innovation, Huian women's dress not only needs to pay attention to the comfort of the dress, but also embody the beauty of the human body to achieve the effect of innovation. The following ways has been mainly adopted in the innovative work of the structure of Huian women's dress.

\subsection{Design of the circumference ease of clothing}

The ease is the increase between the circumference of clothing and the body circumference, the linear distance between the body and the clothing is the gap between clothing and human body. In the design process of clothing structure, in order to ensure that people are comfortable enough to dress Huian women's clothing and reflect modern aesthetics, we need to do well in the design of clothing circumference ease. The design of clothing ease is closely related to the function, aesthetic and modeling of clothing, so if there is an error in the process of ease design, the design of the entire dress structure will fail, causing the deformation and metamorphism in the design of elements.

In general, the basic scope of the circumference ease of body prototype that size is 160/84A is around 10 per cent. Therefore, in the structure drawing, people must do the work of structural design on the basis of the style of the Huian women's clothing. For example, O-type coat has a concise profile and also has a loose modelling, so the increase in the chest circumference of clothes must be done well in the process of design, to increase the overall circumference ease in order to ensure the achievement of the style.

\subsection{Processing of shape of Huian women's dress}

In the processing of shape, Huian women's dress usually uses traditional clipping planes for clothing. But with China's further development in the clothing industry and with the progress of modern cutting technology, our country can use more diversified practices for the production of the modern clothing to promote that the Huian women's dress can meet the people's needs for aesthetic[5]. At the same time, in this way, the stereoscopic sense of Huian women's dress and the compactness of the human body can also be improved. So in the creative design of the Huian women's dress, in order to ensure that the clothing can not only fully reflect the traditional costumes of the artistic conception, at the same time in order to ensure a certain sense of modernity in the process of design, modern technology and plate cutting technology should be used into production of clothing. Thus, through this way, the new Huian women's dress can show the shape and beauty of the human body when people dress them.

\subsection{The innovation of Huian women's dress in color}

When choosing colors, in order to promote the innovative effect of Huian women's dress and make Huian women's dress fashionable and vigorous, it is necessary to apply the international aesthetic color to color matching [6]. At the same time in the waist, cuffs, hem at the amount of 
using color in traditional Huian female costumes beautiful lace cloth clothing patterns, bright color, unique highlights is conducive to further reflect the charm of Huian female costumes. In design, we throw away too fancy coloured fabrics, only choose two colors as the main colors -- yellow and black, which is conducive to ensuring the harmonious collocation of colors. Among them, yellow is the symbol of golden sand and sunshine in traditional Huian women's dress, and black is the symbol of black land and gods, which fully reflects the innovation of Huian women's dress in color.

\section{Epilogue}

To sum up, the dress style is a representative morphological feature developed gradually according to the contemporary aesthetic consciousness and regional characteristics. With the progress and development of the times, when we inherit traditional clothing, we need to integrate and innovate the essence of it with modern clothing. Thus, through this way, Huian women's dress will be further developed, which is more in line with the aesthetic needs of modern people. Only in this way can we carry forward folklore culture and actively transmit folklore fashion elements, which is conducive to the further development of Huian women's dress and promote its inheritance and development in the development process.

\section{References}

[1] Ding Wei. Discussion on the features of bearty in form of Huian women's dress [J]. The Science Education Article Collects, 2011, 15(26): 165-166.

[2] Luo Jing, Cui Rongrong. Sewing skills of Traditional Sweatshirt [J]. Journal of Textile Research, 2012, 33(8): 108-113.

[3] Luo Jing, Cui Rongrong. Study on the structure and function of the Sweatshirt [J]. Shandong economic textile, 2012, 5 (1): 53-56.

[4] Wu Huisha, Lian Min. The application of Huian women's dress in modern clothing design [J]. Tianjin Textile Science \& Technology, 2011, 3(4): 38-41.

[5] Bai Yanfei. Talk shallowly about the inheritance and development of Huian women's dress culture [J]. Shandong economic textile, 2013, 10 (8): 65-66.

[6] Han Jing. The innovative design and application of the structure of Huian women's dress based on modern aesthetics [J]. Xi'an Polytechnic University, 3(23): 10-21. 